\title{
English Language Teachers' Code-switching in Class: ESL Learners' Perceptions
}

\author{
Muhammad Fareed $^{*} \quad$ Samreen Humayun ${ }^{\dagger} \quad$ Huma Akhtar $^{\ddagger}$
}

\begin{abstract}
Code-Switching is generally defined as a shift from one language to another by the speaker during the speech. It is a common linguistic phenomenon in Pakistani classrooms. It is considered to have both positive and negative impact. This exploratory study investigated the perceptions of Pakistani students towards teachers' code-switching during English lectures at tertiary level. Students have different attitudes towards code-switching of teachers in classroom. There is a need to investigate whether it is beneficial or malevolent to switch between two codes in an English classroom and how the students view this alternation between codes. The researchers employed 5point Likert scale questionnaire along with 12 open ended questions to investigate the perceptions of the students towards code-switching of English language teachers during lecture. The findings of the study revealed positive attitude of the students towards teachers' code-switching, however some of the students were of the view that code-switching by teachers restricts their exposure to English.
\end{abstract}

Keywords: English language, Urdu language, code-switching

\section{Introduction}

Pakistan is a multilingual state with English as its official language (Rahman, 2010; H. Khan, 2011; Coleman, 2010). English holds central position in the linguistic scenario of Pakistan as it claims to be language of education, offices, administration, technology, research, etc (Sultana, 2007; Dar, Akhtar, \& Khalid, 2014; Atique \& Khan, 2015; Ali \& Khan, 2015; Dar \& Khan, 2014; Sultan, 2015). Learning English has been of vital importance for students from primary level and it continues to have importance even at tertiary level of their education. Though learning English is considered a challenging task for Pakistani English language learners, yet they realize the importance of learning it.

Varieties of other languages are also spoken in Pakistan and people unconsciously mix and switch between languages in their communication (Rukh, 2014; Iqbal, 2011) Codeswitching has become a very common phenomenon in Pakistan and people commonly switch between Urdu and English. In daily life, on media and even in formal conversation people switch between codes (K. R. Khan, 2004). The occurrence of English in Urdu has become a common phenomenon in textbooks as well (Noor, Anwar, Muhabat, \& Kazemian, 2015). In spoken discourse English teachers switch code during their lectures for different

\footnotetext{
*Assistant Professor, Department of Humanities, NED University of Engineering and Technology, Pakistan E-mail: darfarid@neduet.edu.pk.

$\dagger^{\dagger}$ Assistant Professor, Department of English, Jinnah University for Women, Pakistan

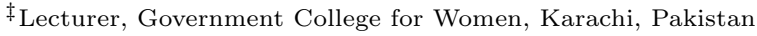


purposes, for example giving instructions, clarifying new vocabulary, managing classrooms etc. Teachers switch from English to Urdu either to explain things better or to build rapport with their students (Gulzar \& Qadir, 2010; Sipra, 2007). Some students are in favor and some are against code-switching in English classes (Gulzar \& Qadir, 2010). When code-switching is used to facilitate, students can have both positive and negative attitude towards it. Hence, the attitude of tertiary level students towards teachers' code-switching needs to be explored in ESL context in Pakistan in order to devise teaching strategies to fulfill needs of the students. This study focuses on students' perception of teachers' code-switching during lectures and specifically the study explored answer to the following question:

- What are the perceptions of Pakistani undergraduate English language learners towards English language teachers' code-switching from English to Urdu language during lectures?

\section{Literature review}

Code-Switching is generally defined as a shift from one language to another by the speaker during the speech. There are varieties of definitions given by different researchers. Early definition by Valdes-Fallis (1978), says that code-switching is an interchangeability of two codes done by transfer, borrowing or mixing of words. Gumperz (1982) defined codeswitching as the juxtaposition of two grammatical systems or sub-systems. There are three types of code-switching: tag- switching, inter-sentential and intra-sentential codeswitching which refer to insertion of tags (for e.g. you know, I mean, etc.), code-switching at word and phrase level, and sentence level respectively (Poplack, 2000; Jingxia, 2010). Gumperz (1982) on the other hand, has discussed situational code-switching and metaphorical switching to refer to the cases whether code-switching is at sentence level or word level as per the need of the situation.

Code-switching is very common in ESL / EFL classrooms throughout the world these days and students have positive and negative attitudes towards code-switching of teachers in classroom (Abdolaziz \& Shahla, 2015; Dar et al., 2014). S. Krashen (1982) suggested that exposure to comprehensible input is necessary for successful language acquisition. If the students cannot understand what has been mentioned, they will not be comfortable in proceeding with a task or retain it in their mind. Therefore, EFL classroom teachers sometimes prefer to use the pupils' L1 to explain and organize a task and to manage behavior in the belief that this will facilitate the medium-centered language-related goals of the lesson (Ellis, 2015). Code-switching occur unconsciously by the teachers and is used as a good strategy in explaining instructions, translating difficult vocabulary, managing class, giving background information and in reducing students' nervousness (Jingxia, 2010; Yao, 2011). Code-switching serves as a mean to provide low proficient learners with the opportunities to communicate and enhance understanding of the lecture (Ahmad \& Jusoff, 2009; Selamat, 2014). Some teachers suggested that code-switching is beneficial to relieve anxious, nervous, frightened, and reluctant students as well as learners with low self-esteem. Code-switching not only increase student's comprehension and application of the material 
but also provide a positive learning environment with the help of good student-teacher relationships (Moghadam, Samad, \& Shahraki, 2012). Majority of ESL learners think that they get benefit because of teachers' code-switching and it helps in learning a language in a better way (Nordin, Ali, Zubir, \& Sadjirin, 2013). According to a research, $64 \%$ of the students give more respect to the teachers who switch code during lectures and most of them believe that code-switching also help them to score better in exams (Alenezi, 2010).

On the other hand, S. D. Krashen (1985) insisted that the students' L1 should not be used in the classroom so as to maximize the exposure of the target language. The more the L2 exposure students receive, the faster the students learn (Ellis, 2015). Yataganbaba and Yildirim (2015) also suggest that L1 should not replace L2. Some teachers are of the opinion that code-switching should be used at beginner or elementary level only and as the level advances it should be limited (Horasan, 2014). The students of English department usually have negative attitude towards code-switching whereas, students from other departments have no objections (Rukh, 2014; Rukh, Saleem, Javeed, \& Mehmood, 2014). Tsukamoto (2012) showed that students prefer to have monolingual classes to enhance their learning and English language skills and appreciated that the classes should be conducted in English without interference of L1. Some students believe that code-switching is not an effective way to achieve their success in language learning (Ling, Jin, Tong, Tarmizi, \& Sahiddan, 2014).

The studies suggested that the educational level of the students play an important role to determine effectiveness of code-switching as a learning strategy. For beginners or lowproficiency learners, for instance, code-switching is an effective strategy to learn, but for intermediate level students more target language input is required therefore code-switching is not approved or liked by their lecturers and students as well (Ling et al., 2014; Jingxia, 2010; Yao, 2011; Horasan, 2014).

\section{Methodology}

Data for this study were collected through 5-point Likert scale questionnaires which consisted of 12 close-ended and 2 open ended questions. The questionnaire was developed by the researcher. The researchers took guidance in tool development form following studies (Ahmad \& Jusoff, 2009; Alenezi, 2010; Selamat, 2014; Ling et al., 2014; Rukh et al., 2014). The tool was checked for self-validity and expert validity. The questionnaire was also piloted and needed changes were made before data collection. Validity is a significant aspect of research and "if a piece of research is invalid then it is worthless" (Cohen, Manion, \& Morrison, 2013). The question of validity is important as it emphasizes on ensuring whether the results of the research can be generalised to population and the similar studies.

Respondents' consent was taken prior to the data collection. They were also informed that participation in the study was voluntary and they could withdraw at any time. The respondents were also assured anonymity. Taking consent and protecting respondents' anonymity are two suggested ways of ensuring ethical consideration. (Creswell, 2012). Quantitative data were analyzed through SPSS version 16.0 and thematic analysis technique was used for qualitative data analysis. 
Sample of the study were 156 undergraduate students from five selected universities in Karachi. Three of the universities are in private sector and the two are in public sector. All of the students in sample were studying English language, as a compulsory subject. Target population of the study are BS, BE and BBA students in Karachi Pakistan. Further details about the sample are given in Table 1 given below.

Table 1

Profile of the sample

\begin{tabular}{|c|c|}
\hline \multicolumn{2}{|l|}{ Gender } \\
\hline Male & Female \\
\hline 38 & 118 \\
\hline \multicolumn{2}{|l|}{ Degree } \\
\hline Bachelors of Science (BS) & 84 \\
\hline Bachelors of Engineering (BE) & 28 \\
\hline Bachelors of Business Administration (BBA) & 34 \\
\hline \multicolumn{2}{|l|}{ University } \\
\hline Private 1 & 35 \\
\hline Private 2 & 30 \\
\hline Private 3 & 34 \\
\hline Public 1 & 28 \\
\hline Public 2 & 29 \\
\hline
\end{tabular}

\section{Findings}

The data were analyzed through descriptive statistics using SPSS while open-ended questions were analyzed through thematic analysis as discussed in (Cohen et al., 2013). The frequency and percentage of the close-ended questionnaire responses are shown in Table 2.

Table 2 provides complete details of the data. This elucidation is about only majority of the responses for each statement in the questionnaire, $57.1 \%$ of the participants believe they understand lecture more easily when the teacher switches code, $73.1 \%$ students agree that Teacher's code-switching helps them in understanding new and difficult vocabularies, concepts and ideas, similarly $64.1 \%$ participants are of the opinion that the teacher's code-switching in task explanation helps them understand the task better, like wise $57.7 \%$ consider code-switching a good technique to motivate students work in a subject, furthermore $55.8 \%$ participants are in favor that teacher's code switching facilitates the learning process.

On the contrary, 70.5\% respondents do not doubt the English teacher's English language competence if the teacher switches code to Urdu language, similarly $82.1 \%$ students disagree that they get confused if the teacher switches to Urdu during lecture, likewise $63.5 \%$ and $51.9 \%$ participants are of the opinion that code-switching does not weaken their overall English language performance and performance in English language speaking skills respectively, moreover $72.4 \%$ students do not agree that they are unable to concentrate on lecture due to code-switching, finally $59 \%$ participants do not feel that the teacher violates English language rules while going to code-switching in Urdu. 


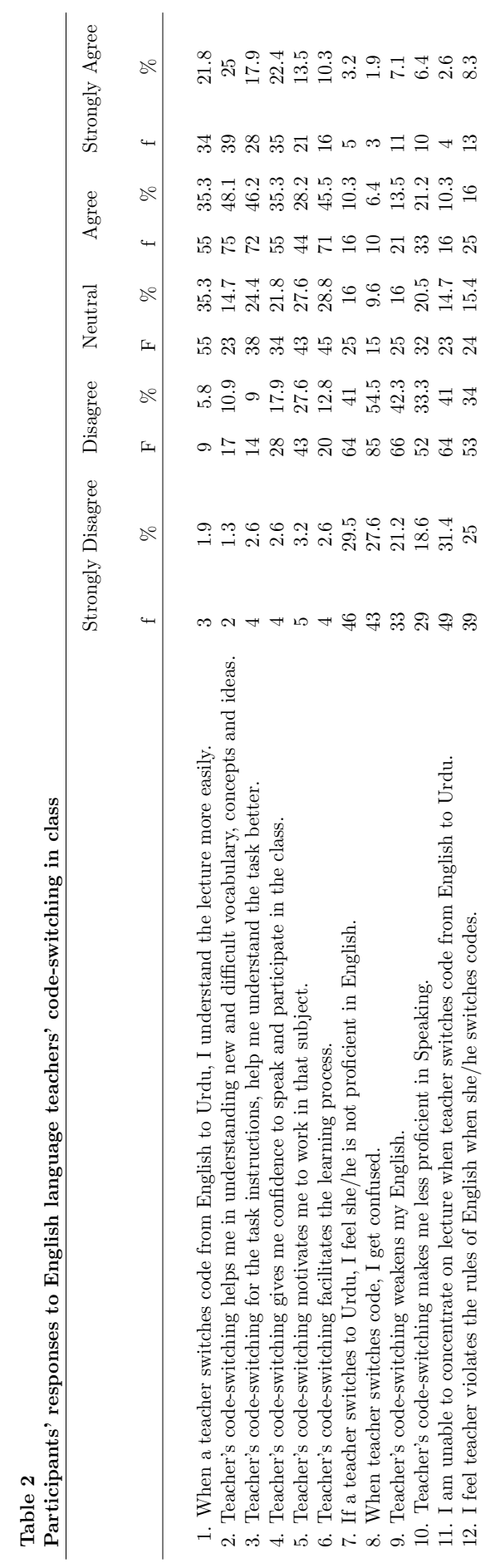


Apart from the close-ended questionnaire, respondents were asked about the advantages through open-ended questions. Some respondents stated that teachers' CS makes the lecture interactive for the students and he/she is able to build rapport with the students. R133, "It makes the students closer to teacher and understand lecture more easily". R57," it "makes the lecture more interactive at times along with creating an aura of familiarity". Students get the feeling that the teacher can understand them.

It serves the psychological need of the learners as their stress and sense of alienation is mitigated or lessened, if not diminished. R74, "It helps to remove or less[en] the anxiety and stress for the students". It facilitates the learning process for students. R123, "if the teacher does it for students' convenience then it has advantages in learning and understanding". According to many respondents it has very minimum disadvantages. R129, "disadvantages are $0.1 \% "$.

Teachers' CS is beneficial for students coming from diverse background, be they urban areas or rural areas. R143, "Students specially those who come from urban sites, they are more able to understand the lectures because they are not able to speak English or to understand". R137, "students come to learn from many parts of country" and they realize that they can easily interact with the teacher in their language as the teacher is also doing so for them. Some respondents view CS positively as it "enhances mental ability" (R151). Some respondents asserted the need to employ this linguistic strategy only to fulfil the requirements of the students than a sign of teacher's linguistic incompetence. R123, "If the teacher does it for his own convenience then it becomes a hindrance in the learning process. So teachers should do it according to the requirement of students".

Some of the disadvantages were also identified from the responses from open-ended questions. Teachers' CS tends to deviate students from their lecture and they find it distracting. R35, "some students might find it distracting but that's subjective". For some it affects thinking skills of students who should have learned to think in L2 than relying on translating from L1 to L2. R22, "Students need to learn how to think in English, codeswitching would not allow this. They would keep translating in their head and not grasp it". Students rely on translating from one language to the other than understand what is being delivered thus CS impacts thinking abilities of the students.

Students viewed English as an important language and classroom is the only place where they have the opportunities to learn English. R22, "for most [of the] students, they do not have an English speaking atmosphere at home and English language classes are usually the only place where they can practice". Some respondents viewed CS in negative light when it restricts their opportunities for rich exposure to the target language. R75, "[It] 'destroys our SLA [Second Language Acquisition]". CS hinders L2 acquisition for students. Teachers' switching code affects the fluency of lecture and breaks momentum required for understanding on the part of the students. R62, "[It] breaks the motion of the lecture". R42, "the rhythm of the lecture breaks".

Some respondents also opined that it directly influences language of the students specially speaking, listening and vocabulary.R92, "it is simply a root to language loss and places us in between i.e neither the speaker of one language nor that of the second language". CS by teacher in classroom deprives the students of opportunities to improve their listening skills in L2. R45, "[It] weakens our listening ability". Not only speaking, 
CS influences speaking skills of the students negatively. R121, "It has drawbacks for those students who want to speak English fluently by listening their teachers' English". Many respondents (R54, R64, R67, R69,R71, R72, R73, R76, R78,R79, andR81) held CS responsible for their weak vocabulary. R78, "it weakens the vocabulary of the students". Not only linguistic skills but CS has a negative impact on affective traits of the students as they find it difficult to face audience because of less exposure to L2. R57, "[It] makes the students to lose confidence in addressing an audience in fluent English".

R104 \& R105 raised the question about distinguishing between native language of the teacher and L1 of the students while discussing the role of CS. What language the teacher switches into-Students' L1 or his own L1? If majority speaks Urdu and the teacher speaks Sindhi or Pushto then CS can certainly have drawbacks.

\section{Discussion}

Code-switching is an inevitable linguistic phenomenon of ESL/EFL classrooms. The data revealed that students studying English at undergraduate level hold positive attitude towards teachers' code-switching. The percentages in favor of code-switching ranges between $41.7 \%$ and $82.1 \%$ with an average of $62.41 \%$, on the other hand percentages against code switching range between $7.7 \%$ and $30.8 \%$ with an average of $17.12 \%$. The respondents are of the view that teachers' switching code helps them understand the lecture easily. They also believe that it helps them in understanding difficult vocabulary, concepts and ideas. The students agree that teachers' code-switching for task instruction help in understanding the task better. Jingxia (2010); Yao (2011) also found that teacher's code-switching give students confidence to speak and participate in the class. The respondents showed mixed feelings about the view that teacher's code-switching motivates them to work in that subject. Teacher's code-switching facilitates the learning process.

Most of the respondents disagree that teachers' switching to L1 lends a negative impact on teachers' own proficiency in English. They think that they are comfortable with teachers' code-switching and it does not weaken their English. Ahmad and Jusoff (2009); Selamat (2014) also identified with their data that teachers' code-switching does not obstruct students' understanding of lecture.

Some respondents state that teachers' CS makes the lecture interactive for the students and he/she is able to build rapport with the students. Students get the feeling that the teacher can understand them. It serves the psychological need of the learners as their stress and sense of alienation is mitigated or lessened, if not diminished. Chowdhury (2013) also found that it facilitates the learning process for students. According to many respondents it has very minimum disadvantages. Teachers' CS is beneficial for students coming from diverse background, be they urban areas or rural areas. They realize that they can easily interact with the teacher in their language as the teacher is also doing so for them.

Some of the disadvantages were also identified from the data. Teachers' CS tends to deviate students from their lecture and they find it distracting. For some it affects thinking skills of students who should have learned to think in L2 than relying on translating from L1 to L2. Students rely on translating from one language to the other than understand what is 
being delivered thus CS impacts thinking abilities of the students. Students viewed English as an important language and classroom is the only place where they have the opportunities to learn English. Some respondents viewed CS in negative light when it restricts their opportunities for rich exposure to the target language. CS hinders L2 acquisition for students. This was also found by Tsukamoto (2012) whose study in Japan showed that students have negative perception of teachers' code-switching Teachers' switching code affects the fluency of lecture and breaks momentum required for understanding on the part of the students. Some respondents also opined that it directly influences language of the students specially speaking, listening and vocabulary. CS by teacher in classroom deprives the students of opportunities to improve their listening skills in L2. Not only speaking, CS influences speaking skills of the students negatively. Many respondents held CS responsible for their weak vocabulary. Not only linguistic skills but CS has a negative impact on affective traits of the students as they find it difficult to face audience because of less exposure to L2. S. D. Krashen (1985) had also insisted that the students'L1 should not be used in the classroom so as to maximize the exposure of the target language. The data revealed that students have positive attitude towards the use of L1 in classrooms in the form of code-switching but some respondents perceive the excessive use of code-switching as detrimental for their own language skills.

\section{Conclusion}

Code-switching and code-mixing are frequently employed linguistic strategies in multilingual classrooms such as in Pakistan. The study aimed to explore the perceptions of the ESL/EFL learners towards teachers' code-switching in English classrooms during lecture. It used a survey questionnaire which was consisted of 12 close-ended and 2 open-ended questions to achieve the objective of the study. The ESL/EFL learners from five private and public institutions and different educational programs: BS, BE and BBA were selected to provide their perceptions of the use of $\mathrm{L} 1$ in their classrooms. The data revealed positive attitude of the students towards teachers' code-switching, however some of the students were of the view that code-switching by teachers restricts their exposure to English. The study was limited to the perceptions of students only and teachers' perceptions were not part of the research scope. The study concludes that code-switching is frequently employed to facilitate ESL students at undergraduate level in Pakistani classrooms therefore, it receives differing attitude from the students. 


\section{References}

Abdolaziz, R., \& Shahla, S. (2015). Teachers and students' perceptions of code switching in aviation language learning courses. International Journal of Research Studies in Language Learning, 5(3), 3-18.

Ahmad, B. H., \& Jusoff, K. (2009). Teachers' code-switching in classroom instructions for low English proficient learners. English Language Teaching, 2(2), 49-60.

Alenezi, A. A. (2010). Students' language attitude towards using code-switching as a medium of instruction in the college of health sciences: An exploratory study. ARE$C L S, 7,1-22$.

Ali, M., \& Khan, I. (2015). Teachers' Perceptions Regarding the Factors Affecting English Essay Writing of O Level Students. Journal of Education 85 Social Sciences, 3(1), 173-197.

Atique, S. S., \& Khan, I. (2015). The Writing needs of Business Students: A Teacher's Perception in an EFL context. Journal of Education 8 Social Sciences, 3(2), 231244.

Chowdhury, N. (2013). Classroom code switching of English language teachers at tertiary level: A Bangladeshi perspective. Stamford Journal of English, 7, 40-61. doi: 10 $.3329 /$ sje.v7i0.14462

Cohen, L., Manion, L., \& Morrison, K. (2013). Research methods in education. Routledge.

Coleman, H. (2010). Teaching and learning in Pakistan: The role of language in education.

Creswell, J. W. (2012). Qualitative inquiry and research design: Choosing among five approaches. Sage Publisher.

Dar, M. F., Akhtar, H., \& Khalid, H. (2014). Code-switching in Pakistani English language classrooms: perceptions of English language teachers. Journal of Social Sciences and Interdisciplinary Research, 2(2), 16-26.

Dar, M. F., \& Khan, I. (2014). Oral Communication Apprehension Among Undergraduate Engineering Students in Pakistan. Journal of Education \& Social Sciences, 2(2), 144-153.

Ellis, R. (2015). Oal: Understanding second language acquisition 2nd edition: Oxford applied linguistics. Oxford University Press.

Gulzar, M. A., \& Qadir, S. A. (2010). Issues of language (s) choice and use: A Pakistani perspective. Pakistan Journal of Social Sciences (PJSS), 30(2), 413-424.

Gumperz, J. J. (1982). Discourse strategies (Vol. 1). Cambridge University Press.

Horasan, S. (2014). Code-switching in EFL classrooms and the perceptions of the students and teachers. Journal of Language and Linguistic Studies, 10(1), 31-45.

Iqbal, L. (2011). Linguistic features of code-switching: A study of Urdu/English bilingual teachers' classroom interactions. International Journal of Humanities and Social Science, 1(14), 188-194.

Jingxia, L. (2010). Teachers' code-switching to the L1 in EFL classroom. The Open Applied Linguistics Journal, 3(10), 10-23.

Khan, H. (2011). University students' attitudes towards the status of English in Pakistan. SPELT Quarterly, 26(3), 16-26. 
Khan, K. R. (2004). Classroom bilingual discourse. Language policy planning and practice: A South Asian Perspective.

Krashen, S. (1982). Principles and practice in second language acquisition (Vol. 2). Oxford Pergamon.

Krashen, S. D. (1985). The input hypothesis: Issues and implications. Addison-Wesley Longman Ltd.

Ling, L. Y., Jin, N. Y., Tong, C. S., Tarmizi, M. A., \& Sahiddan, N. (2014). Influence of an English Lecturer's code-switching practice on Students'Confidence in the subject. International Journal of Asian Social Science, 4(2), 226-233.

Moghadam, S. H., Samad, A. A., \& Shahraki, E. R. (2012). Code Switching as a Medium of Instruction in an EFL Classroom. Theory and practice in Language studies, 2(11), 2219-2225.

Noor, M., Anwar, D., Muhabat, F., \& Kazemian, B. (2015). Code-Switching in Urdu Books of Punjab Text Book Board, Lahore, Pakistan. Communication and Linguistics Studies, 1(2), 13-20.

Nordin, N. M., Ali, F. D. R., Zubir, S. I. S. S., \& Sadjirin, R. (2013). ESL Learners Reactions Towards Code Switching in Classroom Settings. Procedia-Social and Behavioral Sciences, 90, 478-487.

Poplack, S. (2000). Sometimes I'll start a sentence in Spanish y termino en espanol: Toward a typology of code-switching (Vol. 18) (No. 2). Routledge, United Kingdom.

Rahman, T. (2010). Language problems and politics in Pakistan. Routledge Publisher, 232-246.

Rukh, S. (2014). A comparative study of students'attitude towards EFL teachers'codeswitching/code-mixing to L1: A case of Commerce and English Discipline students. International Journal of Research in Social Sciences, 4(3), 526-538.

Rukh, S., Saleem, N., Javeed, H. G. M., \& Mehmood, N. (2014). Students' Attitudes towards Teachers' Code-Mixing/Code-Switching to L1 and Its Influence on Their L2 Learning: A Case of Business Students in Sargodha. International Journal of Science and Research, 3(5), 1111-1116.

Selamat, J. T. (2014). Code Switching in the Malaysian ESL Classroom (Unpublished doctoral dissertation). University of Otago.

Sipra, M. A. (2007). Bilingualism as teaching aid in a language class: L1 as a facilitator in teaching/learning process of L2 at intermediate/certificate level (Unpublished doctoral dissertation). National University of Modern Languages.

Sultan, S. (2015). Syntactic Errors in Pakistani Undergraduate Students' Written English. Journal of Education \&5 Social Sciences, 3(2), 245-259.

Sultana, N. (2007). The Role of Media in the Development and Promotion of English in Pakistan.

Tsukamoto, M. (2012). Students' perception of teachers' language use in an efl classroom. Retrieved from http://ir-lib.wilmina.ac.jp/dspace/bitstream/10775/ 2438/1/d2011_08.pdf

Valdes-Fallis, G. (1978). Code-switching among bilingual Mexican-American women: Towards an understanding of sex-related language alternation. International Journal of the Sociology of Language, 1978(17), 65-72. 
Yao, M. (2011). On attitudes to teachers' code-switching in EFL classes. World journal of English language, 1(1), 19-29.

Yataganbaba, E., \& Yildirim, R. (2015). EFL Teachers' Code Switching in Turkish Secondary EFL Young Language Learner Classrooms. International Journal of Linguistics, 7(1), 82-96. 